Para un estudio fenomenológico de los valores de intimidad del espacio interior, la casa es, sin duda alguna, un ser privilegiado, siempre y cuando se considere la casa a la vez en su unidad y su complejidad, tratando de integrar todos sus valores particulares en un valor fundamental. La casa nos brindará a un tiempo imágenes dispersas y un cuerpo de imágenes. En ambos casos, demostraremos que la imaginación aumenta los valores de la realidad. Una especie de atracción de imágenes concentra a éstas en torno de la casa.

Gastón Bachelard

\title{
Casa y museo en la poesía de Ovidio Ortega ${ }^{1}$
}

El escritor y compositor musical Ovidio Ortega Reyes (San Marcos, 1955) fue galardonado con el Primer Premio del Certamen de Literatura "María Teresa Sánchez" 2017, en la rama de poesía, por el texto Un día mi casa se convirtió en museo. El premio fue entregado por el Doctor Ovidio Reyes Ramírez, Presidente del Banco Central de Nicaragua, institución que auspicia este concurso, en ceremonia pública realizada en el auditorio de la Biblioteca del BCN, el 9 de octubre de este año.

En el poemario Un día mi casa se convirtió en museo, el hablante lírico de este texto de Ovidio Ortega, nos hace recorrer una vivienda guiados por una cicerone como si de la visita a un museo se tratara. El recorrido o viaje poético se realiza atravesando el espacio del domus, con la lectura de textos titulados y dispuestos en la siguiente serie: Frente a la puerta, Sala de estar, Dormitorio con ventana a un muro, Cocina, Patio de tender la ropa, La puerta del retrete, Cuarto de oficio, El cuarto de huéspedes y Fin del recorrido.

¿Por qué una casa se convierte en museo? ¿Cómo el poeta logra ese tránsito de la vida en el domus a la congelada exhibición de un museo? ¿Qué papel juega el tiempo y la corruptible en este desgaste del

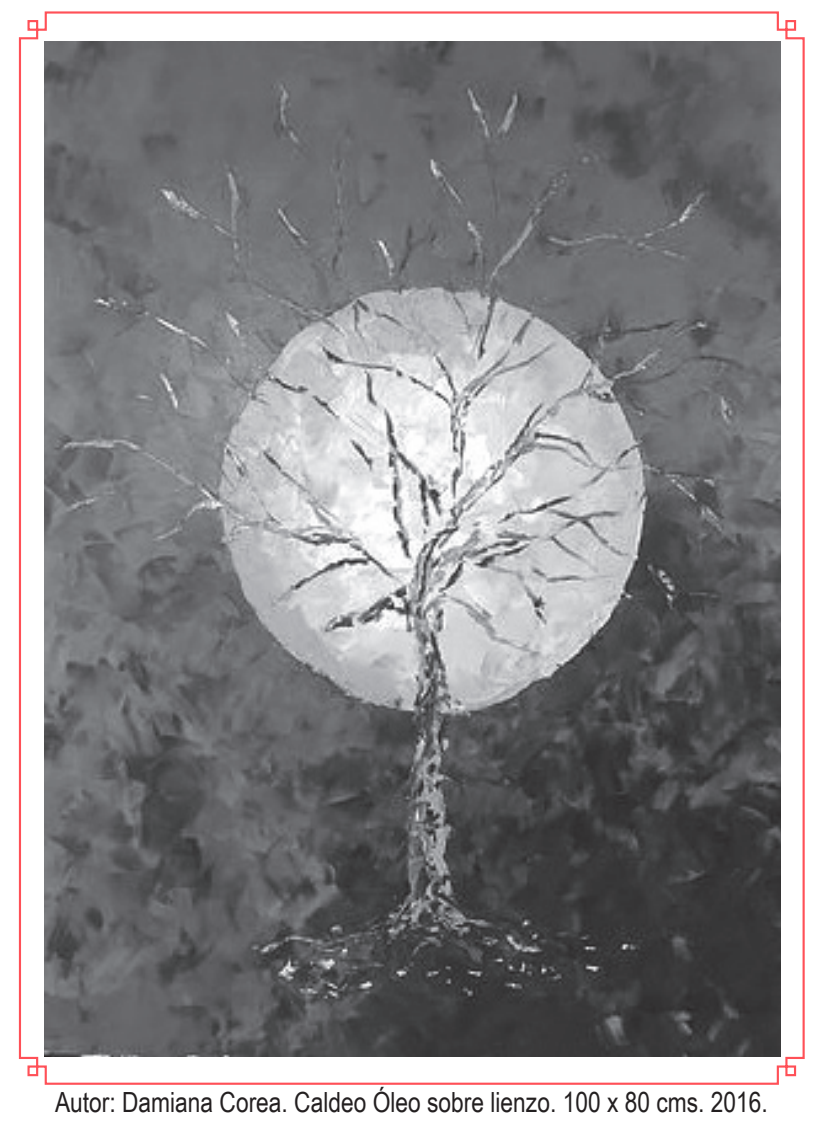
ser?

1 Ovidio Ortega, (1955) nacido en San Marcos, Carazo, de profesión sociólogo, con obra como compositor musical y escritor de literatura infantil. Alguna de su poesía ha sido publicada anteriormente en la revista Los Conjurados (No. 1 /Septiembre 1995) y Revista Cultura de Paz (No. 20 / marzo - abril 1999).

2 Poeta y escritor nicaragüense. Presidente Honorario del Centro Nicaragüense de Escritores (CNE). 


\section{Literatura}

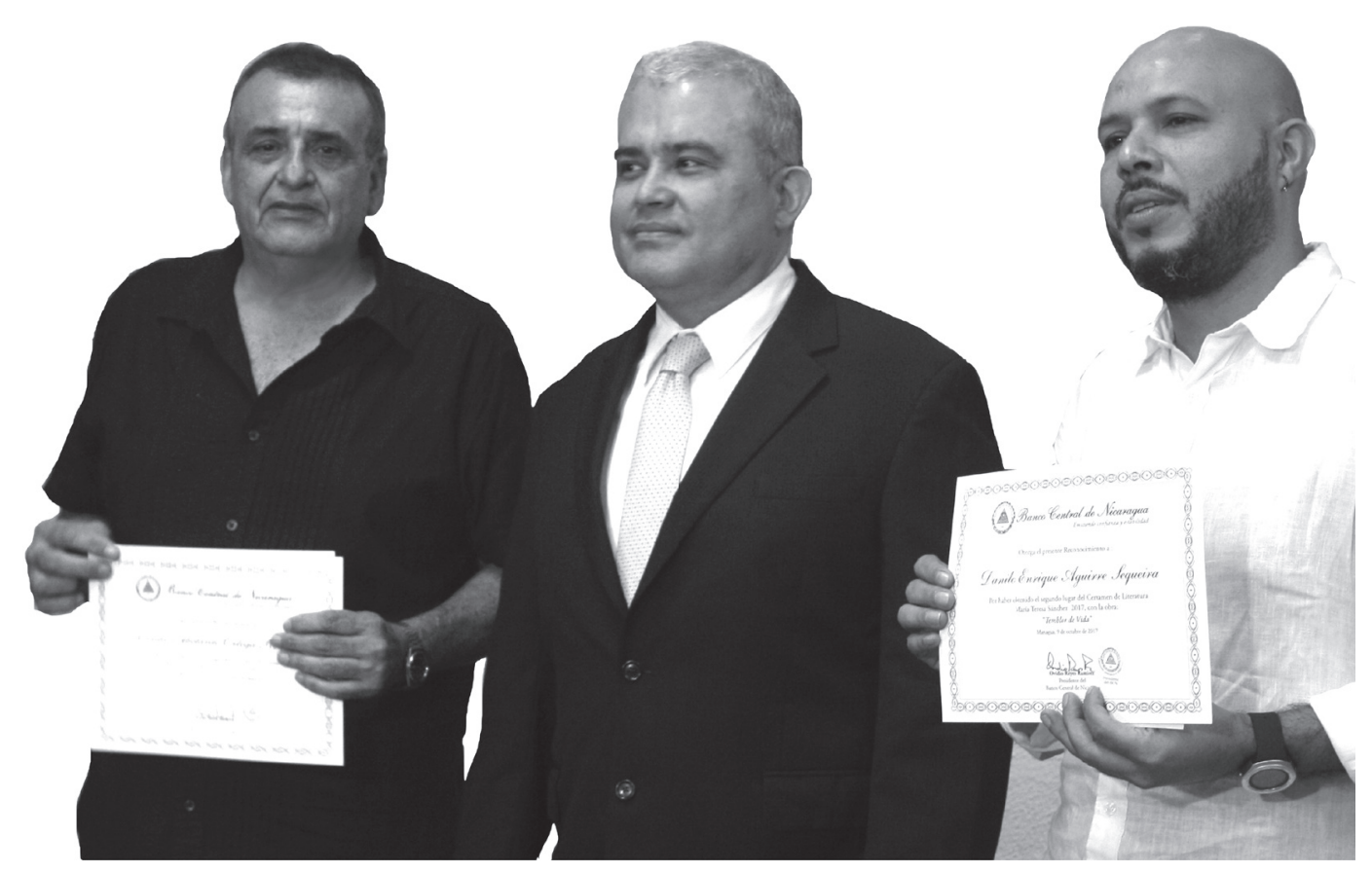

El Maestro Ovidio Ortega, escritor y compositor musical, galardonado con el Primer Premio de Literatura "María Teresa Sánchez 2017"; Dr. Leonardo Ovidio Reyes, Presidente del Banco Central de Nicaragua (BCN) y el Poeta Danilo Enrique Aguirre Sequeira, ganador del segundo lugar.

Con unos versos precisos, cadenciosos y eficaces, Ortega nos entrega una visión de la existencia de un ser humano, cuyos logros -por muy grandes que sean- nunca alcanzan las expectativas imaginadas o soñadas. Esa brecha que hay en todo ser humano entre la flor de la ilusión y el cardo de lo concreto. Una conciencia del devenir desgaste y ceniza de los seres, los entes y las cosas sometidas a lo implacable del tiempo: como una visión saturada de relojes, sombras viradas en sepia e/ identidades descoloridas por la resolana de la tarde, todas/presencias condenadas al/anonimato de las cenizas./(Cosas que penan sin huella/ porque cada engranaje de su/ sentido fue diseminado por toda la nada/ tras el descarrilamiento mortal de la memoria).

Un ser poético, humano, deja su huella, hálito y élan en los distintos ambientes de una casa. Esos signos, marcas y señales, son sometidos a lo corrosivo del tiempo, a la labor de la araña, a la tala de la naturaleza, a la obsolescencia de la madera, a la fatiga de los metales, a la contaminación del ambiente y a una dulce tristeza existencial que nunca llega a angustia, porque el inevitable fin se conoce: Despierto muriendo./ El corazón en picada./ El alma sin lugar./ Despierto agónico/ con el cuento rápido de mi vida frente a mis ojos/como cuando realmente muero.

Un día mi casa se convirtió en museo de Ovidio Ortega, es un texto extraordinario por su calidad, su apertura experimental como escritura y que inaugura una visión poética de mundo que siempre nos va a recordar que la existencia se ve sometida al gasto, a la ceniza, a la nada: Un día todo termina:/ Las luces de la ciudad dejan su lugar a las galaxias/ y el pensamiento migra al caos en busca de/ espejos para desandar el tiempo./ No existe aquí máscara mortuoria que selle/ el final del recorrido como en otros museos. 


\section{Selección de poemas del libro Un día mi casa se convirtió en museo de Ovidio Ortega Reyes}

\section{Dormitorio con ventana a un muro \\ (Primera Mirada)}

Frente a la puerta del dormitorio reniego de la versión mistificada de la guía. No,/ escucho su discurso de oficiante lector de los sentidos,/ posibles, su relato de las coincidencias de esta pieza de tres por cuatro, alguna vez frontera de un verdor indescriptible, escarnecida después por una terrible muralla de/ concreto, hierro y serpentinas cuyos filos duelen en la distancia mas no tocan ese miserable fragmento de azul, la mirilla por donde pasaba un amor inconcluso/ entre detalles de nube o se arrebañaban las palabras victimadas por un verso.

(Segunda mirada)

Aquí la cama:

La vela de hacerse a la noche entre conspiraciones de tormenta y espectros liberados de su maldición de/ abstinencia; aquí, el epicentro del tiempo sin imágenes de horizonte y mañana. Aquí la cama, condena perpetua dimensión indefendible del alma, edén absoluto.

No quiero escuchar de la guía pesadillas inenarrables o delirios de muerte, el asalto de las horas de asfixia y/ arrepentimiento; solo quiero sensaciones de náufrago, muerte soleada, vida deslizando en brazos suaves de arena.

(Tercera Mirada)

Hay un armario rectangular como el cajón de un/ mago

que debió guardar la ropa de dormir, salir,/ permanecer o esconderse;

no recuerdo cómo me vestía, cuál era mi color favorito, cómo combinaba esas piezas de utilería que el/ museo ha reconstruido con fines didácticos $y$ al fin y al cabo pertenecieron a otra persona.

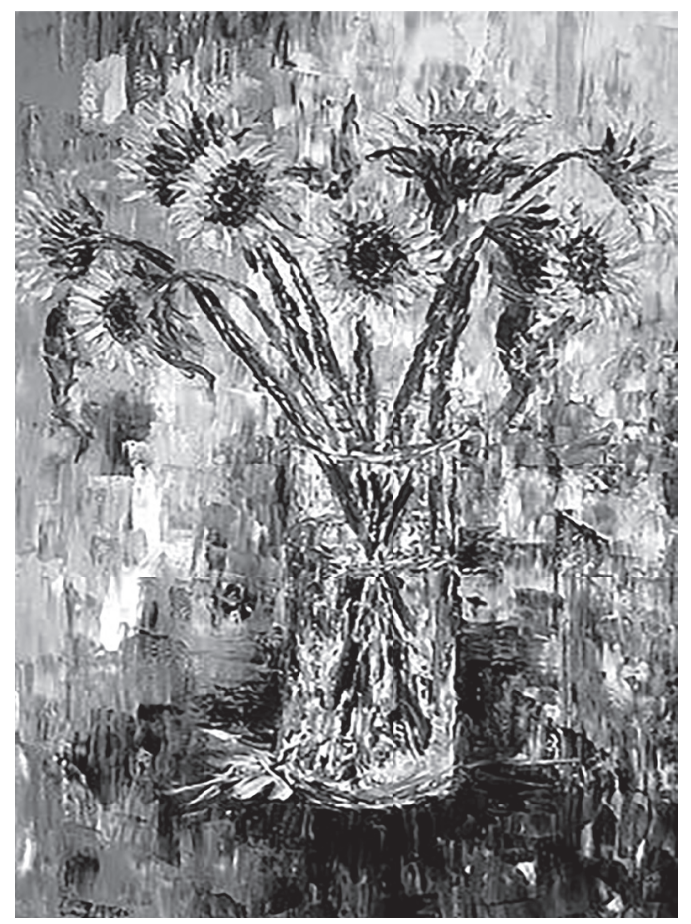

Autor: Damiana Corea. Título: Girasoles. $115 \times 80 \mathrm{cms}$ Óleo sobre lienzo. 


\section{Literatura}

Tengo el recuerdo lejano de una camisa blanca, un pantalón de igual color

y un sombrero también blanco cruzado por una/ cinta negra.

Imagino o recuerdo

el atuendo de tardear en un parque bullicioso donde solía espantar la soledad nuestra de cada/ tarde de domingo;

hay gritos de juego,

pregones de vendedor,

llamados al último día del mundo,

y el nombre de dios en boca de los mendigos

\section{Cocina}

(Primera mirada)

Hay una estufa sin horno descansando en una/ mesa pequeña, abajo un cilindro de gas propano del más/ pequeño y barato;

una armazón sin puertas de un palmo de fondo/ exhibe un tarro de café,

una lata de azúcar y un recipiente para la sal, desgarbado, precario, manoseado y casi roto, como todos los depósitos del mundo donde suele/ vivir la sal, la guía

olvida la cita textual del dueño de casa

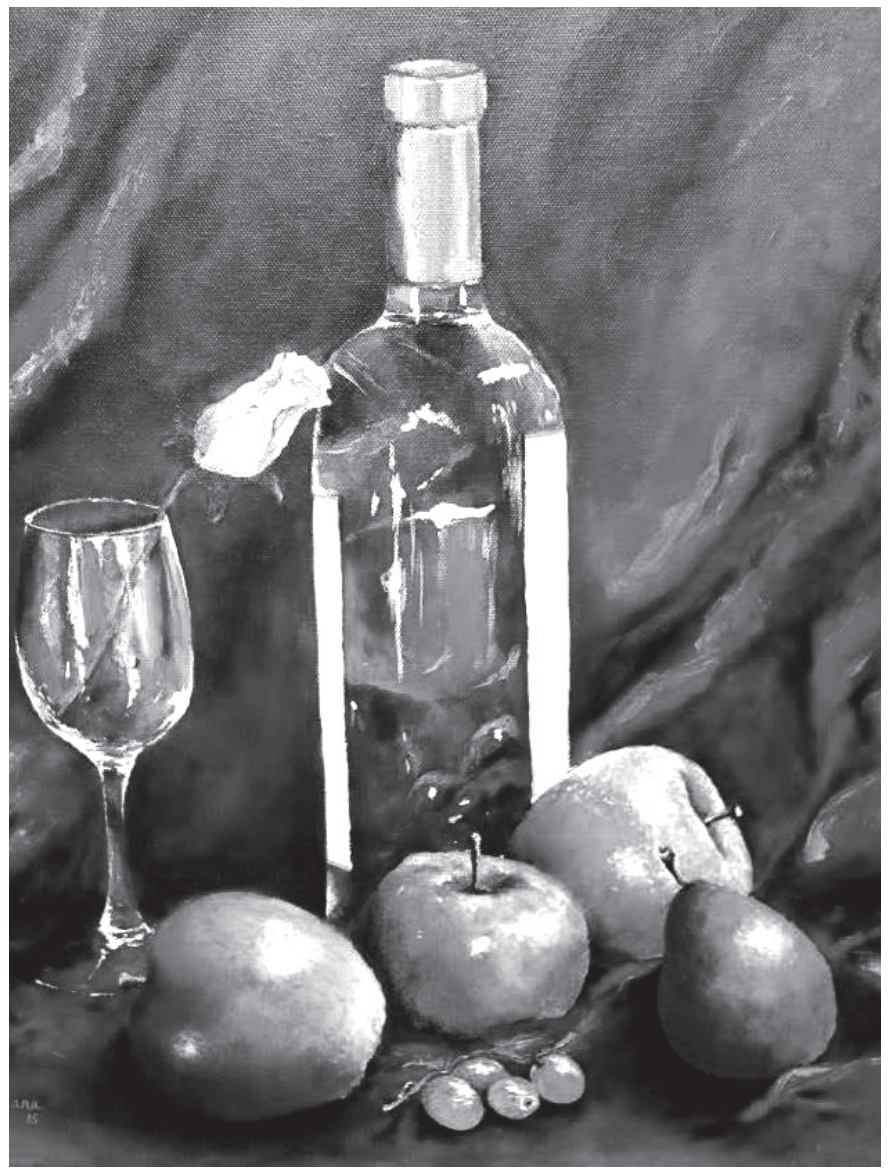

sobre todos aquellos quienes fueron la sal del/

mundo

y vivieron en los peores recipientes de toda la/ creación, mientras

un malestar necio parecido al hambre me/

recuerda el olor del arroz

tostado en dorado antiguo como el brillo de tus/ cabellos,

fragancia de raíces y naturaleza en eclosión.

Me mira esa estufa que conozco como mis penas, los trastos de hervir, freír, cocer y los que no/ conocen

otra cosa más que el agua,

los que nunca ahúman la leche,

aquellos que conocieron el horno y lo extrañan/

para siempre jamás,

los cacharros que nunca tiramos porque algún/

día saldremos

a buscar el asa, la tapa, la pesa, a soldar el/ agujero,

Autor: Damiana Corea

mientras las paredes convocan cada deseo al/ rincón

como un traste más confundido en el camino.

Los quemadores gastados alternan sus toses, parpadeos, apneas, muertes repentinas,

y sonidos susurrantes como advertencias de/ áspid,

para llevar al primer café del día

que libo sombrío

aún antes de despertar a la encrucijada de los/

callejones sin salida

donde se inventó la ilusión del pan

o la amnesia del plato en la mesa;

hubo una hora en que las manos sonámbulas/

traspasaban oscuridades

en busca de agua y lumbre,

adictas al hervor derramado que da nombre a los/ días. 


\section{Literatura}

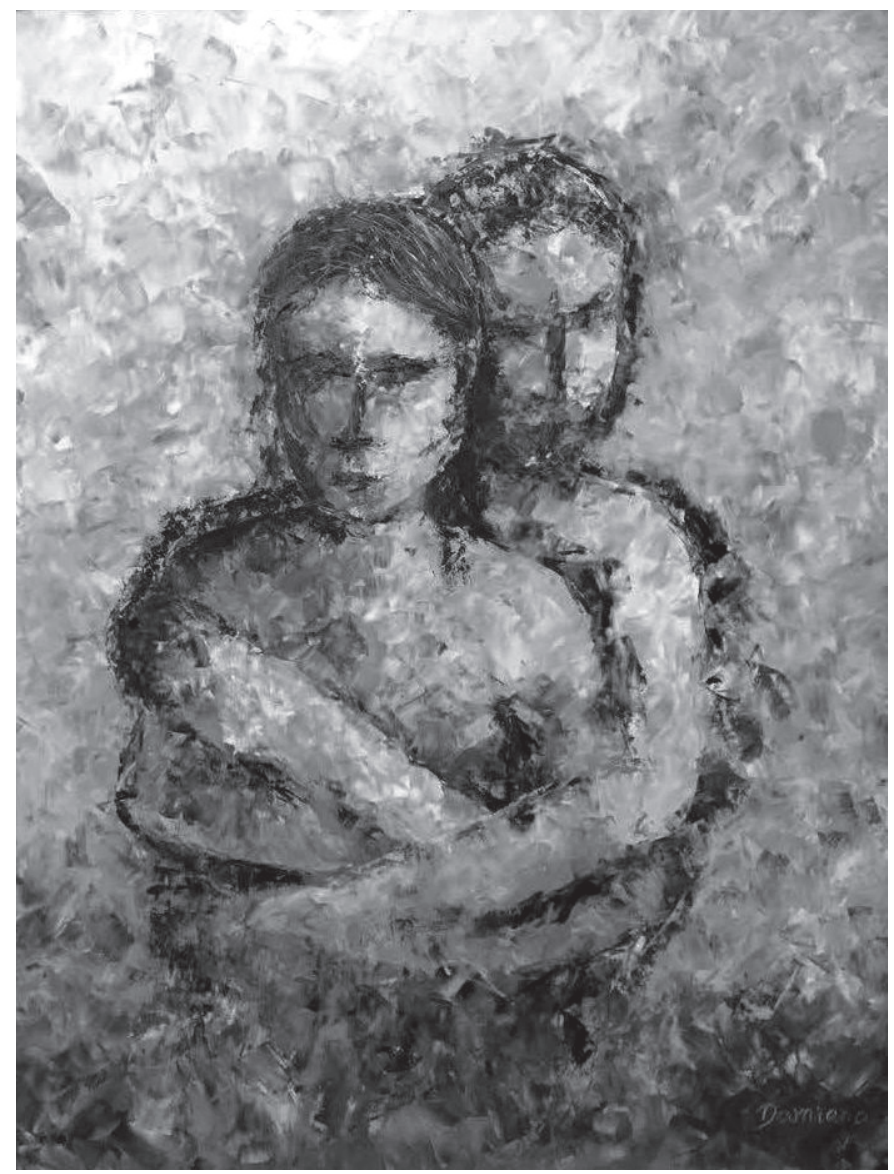

Autor: Damiana Corea. El abrazo. Óleo sobre lienzo. 100 x 80 cms. 2015.

(Inserto con título Despierto)

Despierto muriendo.

El corazón en picada.

El alma sin lugar.

Despierto agónico

con el cuento rápido de mi vida frente a mis ojos,

como cuando realmente muero.

(Segunda Mirada)

Hay una mesa para dos que de algún modo se las ha arreglado para robarse el mejor pedazo de la ventana que da a la callejuela, una mesa de frotar pedernalesy encender/ hogueras

mientras se respira la miel ácida de la savia amaneciendo en mis manos como el calor de tus/ manos al cruzar la calle

hasta que la travesía fue volviéndose más/ peligrosa, mis piernas más lentas, mis reflejos más torpes, la vida más corta

y el café se fue enfriando como una vista $\sin /$ cortinas

a los ojos harto cansados de ver la ventana

\section{Patio de tender la ropa}

Los visitantes solo ven un muro

y un espacio tan ancho como seis ladrillos que algún día - dije-

colindó con la ilusión de un verdor infinito; el reino de espátulas múltiples en veladuras de guayabos y chagüites, el caleidoscopio de floripondios y sardinillos, paraíso desmentido

para que el cielo se nombrara entre las cosas/ fatales.

El sol, sin embargo

da de lleno al patio una semana al año;

son días de ropas olorosas

a lejanías de luna y autobiografías recién/ planchadas,

prestas a habitar entre maderas antiguas de/ cedro

y espíritus perfumados de Ylang y reseda.

Días que pasan haciendo surcos en tu pelo/

mojado,

con peine de carey y caricias de abuela, días de ver tu desnudez a mediodía

iluminada en rubor de buganvilias.

Soles que se van perdiendo en octubre, cuando se torna agridulce el rastro de la/ primavera.

Una fila de gente silenciosa está paralizada/

frente al muro

rendida al miedo,

a la rigidez de la línea erigiendo babeles,/

rascacielos y prisiones,

o la fe que todo cuanto se disemina debe/ retenerse, lo que confunde tiene que encerrarse,

y lo que ríe silenciarse, pero

los gatos se enamoran y cantan entre las/

serpentinas,

las palomas se acicalan,

y las plantas trepadoras 


\section{Literatura}

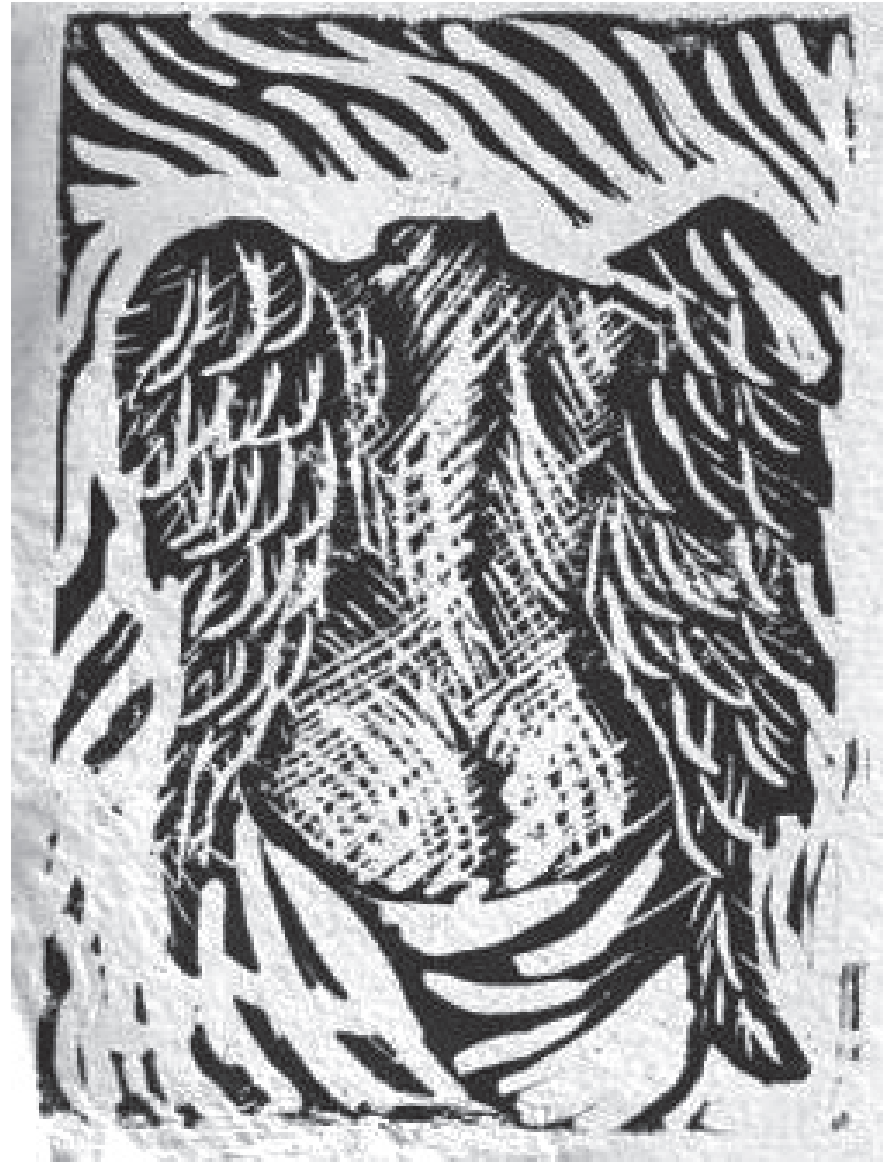

Autor: Damiana Corea - Ángel de Pompeya Linograbado sobre papel reciclado. $15 \times 10 \mathrm{~cm} .2017$.

van desacralizando las texturas repelentes de la/ argamasa,

negando sus mandamientos desde la/

profundidad del verde.

Una calala siembra en la cresta del muro un/

amarillo

que vuela como algunas mariposas

y no tengo un nombre para llamar a esta ilusión/ de mundo.

\section{Cuarto de oficio}

Hay una mentira en la arquitectura

llamada cuarto de oficio,

un reducto atrapado entre sala, dormitorio y/

cocina,

territorio ignorado porque parece no existir y se/ oculta

ajeno al tiempo; yo mismo

a veces paso de largo mientras lo busco

o tropiezo con él por instinto.

En algún lugar de esta casa - dice la guía con/

autosuficiente humildad -

nadie puede estar seguro dónde exactamente

nacieron sus versos;

se especula de la mesa que se esconde detrás del/

café y la sal de la cocina

dueña de un ángulo de la calle, su bullicio e/

invenciones de árbol,

o el azul cautivo entre bloque y serpentina,

el frío amable con sombra de tamarindo.

Pero eso ya no importa, concluye rotunda, como si supiera de las palabras que devienen/ astros

\section{El Cuarto de huéspedes}

Por aquí pasaron las sombras más amables de la/ lluvia,

y se tendieron a ras del sueño en el delgado/ colchón de espuma,

a descansar de la persecución diaria de las/

preguntas.

Quizá en algo se parece

la puerta que tiene el descaro de rechinar como si/ riera;

y su ventana larga con vista a la calle, cerrada/

siempre

para impedir el paso de las hojillas del/

tamarindo.

Sobre el colchón de espuma una mochila/ expedicionaria,

libreta de notas y un libro de Aldous Huxley;

a un lado un par de sandalias de cuero y un/

cenicero repleto de colillas.

Me parece un pastiche,

un paisaje dramático,

una receta de circunstancias.

Hubo, sí, un fotógrafo belga que retrataba

veletas/ de hierros antiguos

contra los cielos de Lieja

y cantaba a Brel ebrio y nostálgico,

planas las lágrimas como cielos de mapa.

Un neoyorkino que sorteaba la trompeta de Miles/ 


\section{Literatura}

Davis

entre su oído sordo y el humo del café, dueño de una motocicleta y dos loras que se dormían en los solos de contrabajo y saludaban las frases largas del saxofón de/ Coltrane como si fuera la lluvia.

Un florentino de Ocotal endemoniado, lamiendo el lienzo con el color del delirio, porque para pintar una gota, decía, debe existir la obsesión de pintar todo el mar.

Un suizo flaco como una aguja, que comía chocolate y agua, solamente: en invierno solía cuidar vacas en sus encierros en verano hacía estantes para las ferias.

Y una mujer con el marrón de sus ojos siempre en fuga, y romanceros de luna, azahar y cuchillos en el poso del café;

la veo en la distancia encendiendo luces, en los árboles condenados, estampando memorias en los perdederos de mi/ desvelo, desgranando el pan para encontrar siempre el camino de regreso. Pero no recuerdo algún mochilero atormentado, consumiendo la noche en sorbos de nicotina, ni sandalias de discurrir por el paisaje floripondios proféticos, dudas remisas sobre el colchón de espuma.

\section{Fin del recorrido}

Un día todo termina:

Las luces de la ciudad dejan su lugar a las/ galaxias

y el pensamiento migra al caos en busca de espejos para desandar el tiempo.

No existe aquí máscara mortuoria que selle el final del recorrido como en otros museos. La guía anuncia casi con vergüenza el agotamiento de las cronologías los límites de las plastificaciones y los fetiches, lo poco por agregar a las respuestas truncas y cada fragmento guarda silencio mientras/ inicia el desfile de alientos retenidos, murmullos de visitantes resignados

en marcha ordenada hacia la puerta de salida.

Un día sin mucho calor,

despejado como suele ser el umbral de/

noviembre,

un día sin celebración o misterios,

susceptible de interrumpirse y reanudar su/

tedio sin alguna consecuencia,

uno que puede confeccionarse con retazos de/

otros días

sin que la vida lo note.

Un día que emerge a la conciencia acosado por/

sueños cansinos,

y tormento de metáforas ferroviarias donde/

tren, vagón y estación vacía

escancian sus presentimientos de pañuelo y/ adiós

cada vez que los años

excavan en el pecho agujeros de gusano

que duelen como la espera.

Un día con una tarde que junta recuerdos/

extraviados,

ovejas inaprensibles,

nubes que piden la lluvia en la más pura ilusión/

del recuerdo.

Una tarde cuando el mundo se desmonta/

sensación por sensación,

y la muerte llega sin heraldos

o escribanos solitarios pendientes del golpe de/

telón

en una boca jadeando

ConsumatumEst.

Sólo se abren los brazos en remedo metafísico y los ojos contemplan fijos una perspectiva en el/ techo

donde un tren se pierde apenas agitando

su estela blanca, blanquísima de humo.

Los visitantes se han ido,

la guía cierra delicadamente la puerta

y apresura el taconeo cruzando

el jardín de baldosas

donde alguna vez existió un árbol. 